\title{
Apparent Density, Trypanosome Infection Rates and Host Preference of Tsetse Flies in the Sleeping Sickness Endemic Focus of North-Western Uganda
}

Robert Opiro ( $\nabla$ robopiro@gu.ac.ug )

Gulu University Faculty of Science https://orcid.org/0000-0003-4246-9336

Robert Opoke Muni University

Harriet Angwech

Gulu University Faculty of Science

Esther Nakafu

Makerere University

Francis A. Oloya

Gulu University

Geoffrey Openy

Gulu University

Moses Njahira

International Livestock Research Institute

\section{Mercy Macharia}

International Livestock Research Institute

Richard Echodu

Gulu University

Geoffrey M. Malinga

Gulu University

Elizabeth A. Opiyo

Gulu University Faculty of Science

\section{Research article}

Keywords: C01, Cytb, nested PCR, reservoir hosts, mixed infection, Adjumani, Moyo

Posted Date: July 17th, 2020

DOI: https://doi.org/10.21203/rs.3.rs-43888/v1

License: (c) (i) This work is licensed under a Creative Commons Attribution 4.0 International License. Read Full License 


\section{Abstract}

Background:African trypanosomiasis, caused by protozoa of the genus Trypanosoma and transmitted by the tsetse fly, is a serious parasitic disease of humans and animals. Reliable data on the vector distribution, feeding preference and the trypanosome species they carry is pertinent to planning sustainable control strategies.

Methodology: We deployed 109 biconical traps in 10 villages in two districts of northwestern Uganda to obtain information on the apparent density, trypanosome infection rates and blood meal sources of tsetse flies. A subset of the collected samples was analyzed for detection of trypanosomes species and sub-species using a nested PCR protocol based on primers amplifying the Internal Transcribed Spacer (ITS) region of ribosomal DNA. 34 bloodengorged adult tsetse midguts were analyzed for blood meal sources by sequencing of the mitochondrial cytochrome c oxidase 1 (COI) and cytochrome b (cytb) genes.

Results: Out of the 109 traps deployed, we captured 622 Glossina fuscipes fuscipes tsetse flies (269 males and 353 females). Apparent density (AD) ranged from 0.6 to 3.7 flies/trap/day in the two districts. $29(10.7 \%)$ of the flies were infected with one or more trypanosome species, with infection rate significantly associated with age group $\left(x^{2}=\right.$ $29.733, d f=2, p<0.05)$ but not with $\operatorname{sex}\left(x^{2}=0.43, d f=1, p=0.835\right)$ and district of origin $\left(x^{2}=1.374, d f=1, p=\right.$ 0.241). Nested PCR revealed several species of trypanosomes: T. vivax (62.1\%), T. congolense $(24.14 \%)$, and $T$. brucei and $T$. simiae each at $6.89 \%$. Blood meal analyses revealed five principal vertebrate hosts, namely, cattle (Bos taurus), humans (Homo sapiens), Nile monitor lizard (Varanus niloticus), African mud turtle (Pelusio schapini) and the African Savanna elephant (Loxodonta africana).

Conclusion: We found a moderately high infection rate at $10.78 \%$, with all infections attributed to trypanosome species that are causative agents for the animal disease only. However, more validation using large-scale passive and active screening of human and tsetse samples should be done. Cattle and humans appear to be the most important tsetse hosts in the region and should be considered in the design of interventions.

\section{Background}

African trypanosomes, members of the genus Trypanosoma, are flagellated parasitic protozoa that cause zoonotic diseases generally known as African trypanosomiasis. The diseases are known as sleeping sickness (or human African trypanosomiasis, HAT) and Nagana (or animal African trypanosomiasis, AAT) and are inextricably linked in humans and livestock, respectively. HAT still remains one of the most devastating neglected tropical diseases of poverty that causes severe morbidity and mortality, with over 70 million people at risk of being infected in SubSaharan Africa [1]. AAT on the other hand is a major constraint to livestock production causing massive economic burden in sub-Saharan Africa. The Food and Agricultural Organization of the United Nations (FAO) estimates that Africa loses up to US\$1.5 billion annually as a result of the disease [2]. Thus, these diseases together, have both negative health and economic impacts.

In Uganda vector-borne diseases, notably AAT presents a major constraint to livestock productivity [3, 4]. Poor livestock health as a result of AAT denies farmers draught power and manure thereby contributing to poverty and hunger in the tsetse-infested areas $[5,6]$. Regarding HAT, despite the current small number of cases, Uganda is the only country where both the chronic (caused by $T$. b. gambiense) and acute (caused by $T$. b. rhodesiense) forms of the disease occur. The T. b. gambiense form occurs in the northwestern corner of the country while T. b. rhodesiense is in the Eastern and Southern part of Uganda. Evidence already point to a danger of merger of the two HAT belts, 
fueled by animal movements [7-9], and vector migration northwards [10-12]. This underscores the need for research geared towards providing information to support sustainable control in the country.

Despite the existence of various drugs effective against AAT, chemoprophylaxis and treatment are expensive and usually ineffective, besides it is impossible to treat all wild and domestic hosts [13]. Furthermore, improper use of therapeutic drugs has led to the emergence of drug resistance in animal trypanosomes [14, 15]. Vector control therefore offers a more viable strategy to disease management $[16,17]$ and it remains the only available strategy capable of protecting human individuals from acquiring infection [13]. However, effective vector control requires reliable and accurate data on distribution, trypanosome infection status and preferred hosts of the vectors. Therefore, in this study, we assessed the preferred hosts of tsetse (blood meals sources), distribution of trypanosomes and trypanosome infection rates of tsetse flies in the West Nile districts of Adjumani and Moyo. We used the mitochondrial cytochrome c oxidase 1 (COI) and cytochrome b (cyt b) gene sequences for identification of tsetse fly blood meal sources collected from tsetse midguts. We also detected trypanosomes species in tsetse using a nested PCR protocol based on primers amplifying the ITS region of ribosomal DNA.

\section{Methods}

\section{Study sites and sample collection}

The study was carried out in Adjumani $\left(3.3784^{\circ} \mathrm{N}, 31.7822^{\circ} \mathrm{E}\right)$ and Moyo districts $\left(3.6527^{\circ} \mathrm{N}, 31.7281^{\circ} \mathrm{E}\right)$ in northwestern Uganda (Fig. 1). Northwestern Uganda has traditionally been known as an endemic sleeping sickness focus but recent surveys show that there has been a decrease in new cases of HAT [18]. Regarding AAT, there are numerous confirmed and anecdotal reports of the presence of the disease among cattle keeping households. Northwestern Uganda has two rainfall periods that run from March-May and from July-November, with a short dry spell in June and a fairly long period of dryness from December to February. The vegetation is a mixture of forests and savannah, with open woodland, grassland, and shrubbery. Besides, there are several fast running streams passing through subsistence farms with low plains and rolling hills and valleys that slope towards the river Nile.The typical riverine habitats are suitable for Glossina fuscipes fuscipes, the principal tsetse vector in this area. The population is largely rural, practicing mixed crop and livestock farming, consisting of food and cash crops such as tobacco, and livestock, mainly cattle, goats, sheep and pigs.

\section{[Figure 1]}

Tsetse trapping was conducted using biconical traps [19] baited with acetone and cow urine, deployed along suitable habitats, targeting majorly areas of human and animal activities (Fig. 2). At each site, an average of 10 traps were mounted approximately $100 \mathrm{~m}$ apart in different vegetation types for three consecutive days and in well shaded areas to minimize fly mortality due to excessive heat. Information on sex, collection date, trap number, and geographical coordinates of each trap was recorded. To prevent the attack of ants on the flies in the traps, each supporting pole was smeared with grease. Trapped tsetse flies were collected every 24 hours for at least three consecutive days [20]. After each collection, tsetse flies were identified morphologically, counted and sorted into teneral and non-teneral as described by [21]. The tsetse flies were assigned to one of the six age categories, according to the degree of wear or fraying observed on the hind margin of the wing as described by Jackson [22]. After categorizing the wing fray, the actual age of the fly was estimated using directions for estimating the mean age of a sample of tsetse flies as outlined in the FAO Training manual for tsetse control personnel [23]. The ages of tsetse flies based on wing fray categories were later pooled as "young tsetse" (ages 1-2), "old tsetse" (ages 3-4) and "very old tsetse" (ages 5-6) for statistical analysis. Dissection of tsetse tissues (midguts, salivary glands and 
proboscis) was carried out as described in the FAO Training Manual for Tsetse Control Personnel [23]. Trapped flies were dissected in phosphate buffered saline in $2 \%$ glucose under a dissecting microscope. Samples of midguts, salivary glands and proboscis from dissected flies were preserved in $70 \%$ ethanol in sealed eppendorf tubes until required for subsequent DNA extraction and PCR assays.

\section{[Figure 2]}

\section{DNA extraction}

Genomic DNA was extracted from the midguts, proboscis and salivary glands of ethanol-preserved tissues using Purelink ${ }^{\mathrm{TM}}$ extraction kit from Invitrogen following the manufacturer's instructions. The supernatant was used either directly for PCR or stored at $-20^{\circ} \mathrm{C}$. Prior to their use or storage, DNA samples were electrophoresed in a $1 \%$ agarose gel in $0.5 \times$ TBE buffer at $100 \mathrm{~V}$ for 45 mins. The quality of DNA in the sample was then estimated by comparing florescent yield of the sample with standard cut Lambda DNA run alongside the DNA samples. Spectrophotometry (Nano-Drop Technologies, Wilmington, USA) was used for checking the purity of DNA extracted, with the optical density (OD) taken at $260 \mathrm{~nm}$ and $280 \mathrm{~nm}$, and a ratio 260: 280 (260nm: $280 \mathrm{~nm})$ was calculated to provide an estimate of the purity of nucleic acids.

\section{Identification of different trypanosome species}

To detect trypanosome DNA, we employed the nested PCR protocol described by [24], using the same primer sequences but with slight modifications in amplification conditions. The outer primer sequences were ITS1 (5_-GAT TAC GTC CCT GCCATT TG-3), and ITS2 (5-TTG TTC GCT ATC GGTCTT CC-3) and inner primer sequences ITS3 (5GGA AGC AAA AGT CGT AACAAG G-3), and ITS4 (5-TGT TTT CTT TTC CTCCGC TG-3). All primers were obtained from the Bioneer Corporation. PCR amplifications were performed in two PCR rounds. The first round was performed in a final reaction volume of $20 \mu \mathrm{l}$ containing $10 \mathrm{pmol}$ of each primer, the BioneerAccuPower ${ }^{\circledR}$ PCR premix (Bioneer Corporation), and $2 \mu \mathrm{L}$ of each DNA template. The amplification conditions began with 1 cycle of denaturation at 95 ${ }^{\circ} \mathrm{C}$ for $5 \mathrm{~min}$ followed by 40 amplification cycles at $94{ }^{\circ} \mathrm{C}$ for $1 \mathrm{~min}, 55^{\circ} \mathrm{C}$ for $1 \mathrm{~min}$, and $72{ }^{\circ} \mathrm{C}$ for $2 \mathrm{minutes}$. In the second round, $2 \mu \mathrm{L}$ of the amplified product from the first round was placed in a fresh tube and $20 \mu \mathrm{L}$ of the reaction mixture was added as described above for the outer primers, except that the outer primers (ITS1 and 2) were substituted with the inner primers (ITS3 and 4). The amplifications conditions were identical to the one described for the first PCR round. To minimize bias due to false positives during repeated PCRs, negative controls in which DNA templates were replaced with sterile distilled water as well as positive control DNAs (of each trypanosome species) were included in all PCR reactions. All reactions were carried out in a highly sterilized and dedicated PCR diagnostics lab environment of the BecA-ILRI Hub laboratories with a GeneAmp 9700 thermal cycler PCR system (Applied Biosystems). After the nested PCR, $5 \mu \mathrm{L}$ of the amplified products were loaded on a casted $1.8 \%$ agarose gel, which was subsequently stained with a Gel Red nucleic acid stain, with a 75bp gene marker. These were run in a Mupid ${ }^{\circledR}$ exu Sub-marine electrophoresis gel tank (Helix Technologies Inc. MEXO 0800137) for 45 mins at 100V in 0.5X TBE buffer. The gels were then visualized under ultra-violet illumination and photographed. Trypanosomes species and subspecies were identified by comparing the molecular sizes of their DNA fragments with the documented band sizes of trypanosome species[24].

\section{Identification of tsetse blood meal sources}

To test for the presence of DNA from the blood of vertebrate hosts, samples of DNA from residual blood meal in tsetse midguts were amplified using PCR with universal primers complementary to the conserved region of 
mitochondrial DNA (mtDNA) C01 and cytb gene as detailed in [25]. The primer sequences for the C01 gene was VF1d_t1 (5' TGTAAAACGACGGCCAGTTCTCAACCAACCACAARGAYATYGG- 3') and VR1d_t1 (5'CAGGAAACAGCTATGACTAGACTTCTGGGTGGCCRAARAAYCA- 3') and for the Cyt b was (Cb5'CCATCCAACATCTCAGCATGATGAAA-3') and (Cb2 5'-CCCCTCAGAATGATATTTGTCCTCA-3') as described in Muturi et al. [26] and Kocher et al. [27], respectively. Both PCR reactions were performed in a total volume of $20 \mu$ l containing $10 \mathrm{pmol}$ of each primer, $10 \mathrm{mMTris}-\mathrm{Cl}, \mathrm{pH} 8.3$ and $50 \mathrm{mMKCl}, 1.5 \mathrm{mM} \mathrm{MgCl} 2,2.5 \mathrm{mMdNTPs}, 2 \mu \mathrm{l}$ of the DNA template and 1 unit DreamTaq ${ }^{\mathrm{TM}}$ DNA polymerase (Fermentas Life Sciences). The PCR was then carried out in a GeneAmpPCR System 9700 (Applied Biosystems) thermocycler. The conditions for C01 PCR were as follows: initial denaturation at $94^{\circ} \mathrm{C}$ for 5 minutes, followed by 45 cycles of denaturation at $94^{\circ} \mathrm{C}$ for $30 \mathrm{~s}$, annealing at $55^{\circ} \mathrm{C}$ for 1 minute, and primer extension at $72^{\circ} \mathrm{C}$ for 30 seconds. For Cyt b PCR, conditions were: initial denaturation at $94^{\circ} \mathrm{C}$ for 5 minutes, followed by 40 cycles of denaturation at $94^{\circ} \mathrm{C}$ for $45 \mathrm{~s}$, annealing at $55^{\circ} \mathrm{C}$ for $45 \mathrm{sec}$, and primer extension at $72^{\circ} \mathrm{C}$ for $30 \mathrm{~s}$. Positive and negative controls were included in each PCR assay. The positive controls were cattle genomic DNA obtained from the Animal Health Unit at ILRI Research Laboratories. Negative controls consisted of the Master Mix for each PCR and fresh Milli Q water obtained from the Central Core of the BeCA hub laboratories. Five microlitres of the amplified products were loaded into a casted $1.8 \%$ agarose gel stained with gel red stain, with a $75 \mathrm{bp}$ gene marker, positive controls and negative controls. These were run in either a Mupid ${ }^{\circledR}$-exu Sub-marine electrophoresis (Helix Technologies Inc. MEXO 0800137) or BIO-RAD Sub-cell ${ }^{\circledR}$ GT 9204355RevA gel tanks for 45 mins and 1 hour respectively at $100 \mathrm{~V}$ in $0.5 \mathrm{X}$ TBE buffer. The amplified products were visualized under ultra-violet illumination and a picture of the gel taken using the gel documentation and analysis systems mounted with a high-performance CCD Camera-COHU. The bands were then used to confirm the amplicon size of the $\mathrm{CO} 1$ and cyt b genes.

The PCR products were gel-purified using the GeneJet ${ }^{\text {TM }}$ kit (catalog no K0702 EU) following the manufacturer's instructions and submitted to the BeCA-ILRI Hub Sequencing Unit (Segolip) for sequencing using Bigdye ${ }^{\mathrm{TM}}$ Terminator. Sequencing was done bi-directionally using the inner amplification primers for the C01 and cyt b genes. Consensus sequences were then generated by contiguation functions of the CLC Main Workbench Version 6.6.2 and manually edited, where necessary, by reference to the chromatograms. Vertebrate species were confirmed by sequence alignments with those already deposited in GenBank database using the Basic Local Alignment Search Tool (BLAST, https://blast.ncbi.nIm.nih.gov/Blast.cgi)[28]. Sequences of a given pair-wise alignment from positive PCR products with high percentage similarity (identity matches of 90-98\%) and lowest E-values were selected as the most likely species of host.

\section{Data analyses}

The average Apparent density (AD), expressed as the average number of flies caught per trap per day (flies/ trap/ day or FTD), was calculated to obtain the data on tsetse distribution in the area for each trapping site using the formula: $F T D=\Sigma F / T \times D$, where, $\Sigma F$ is the total number of tsetse flies caught, $T$ is the number of traps deployed and $D$ is the number of days of trapping in the field. Tsetse infection rates were calculated by dividing the number of flies infected with trypanosomes by the total number of flies analysed, and expressed as percentages. Pearson chi-square goodness of-fit-tests $\left(\chi^{2}\right)$ and logistic regression were employed to determine the association of tsetse infection rates with fly's sex, district of origin, and age based on wing fray category. Values of $p$-value $<0.05$ were considered significant at $95 \%$ confidence interval $(\mathrm{Cl})$. Independent samples t-test was conducted to compare whether the average number of flies caught per trap per day differ between the two districts under study. All statistical tests were performed using SPSS software (version 21.0.1, SPSS Inc., Chicago, IL, USA).

\section{Results}




\section{Entomological survey}

We caught 622 tsetse flies (269 males and 353 females) (Table 1) from 109 traps deployed in 10 villages (five in each district). Of these, 320 flies were caught from Adjumani and 302 from Moyo districts, respectively. All the tsetse flies caught belonged to the Glossina fuscipes fuscipes species. Apparent density (AD) ranged from 0.58 to 3.67 tsetse flies per trap per day for all villages. However, the average FTD in the two districts did not differ significantly (Independent samples t-test, $t=0.35, \mathrm{df}=8, \mathrm{p}=0.458$ ). The average age of flies caught in Adjumani district was 30 days (Mean Wing Fray Value, MWFV = 3.8) while for Moyo district was 25 days old (MWFV = 3.3) $($ Table 1).

\section{[Table 1]}

\section{Trypanosome infection rates}

We analysed $43 \%(272 / 622)$ of the collected tsetse samples for detection of trypanosomes. The overall infection rate was $10.67 \%$ (29/272). There was no significant association of sex of tsetse with trypanosome infection $\left(\chi^{2}=0.43\right.$, df $=1, p=0.84)$. Furthermore, the trypanosome infection rate was not significantly associated with the district location

$\left(X^{2}=1.37, d f=1, p=0.24\right)$ and among villages $\left(X^{2}=11.49, d f=9, p=0.244\right)$. In Adjumani district, the villages with the highest infection rates were Olobo (18.33\%), followed by Oringya (14.2\%), Osugo East (11.42\%) and Pagirinya (3.45\%). In Moyo District, the highest infection rates were recorded in Orubakulem (11.67\%), followed by Ori (6.25\%) and Lea (10\%). There was no infected fly in Cefo and Moyipi villages (Table 2).

\section{[Table 2]}

There was, however, a significant association between tsetse age group based on wing fray category and rate of trypanosome infection $\left(x^{2}=29.73, d f=2, p<0.05\right)$. The risk of trypanosome infection was higher in very old flies by $28 \%$ (odds ratio, OR $0.28 ; 95 \% \mathrm{CL}(0.108-0.702) ; \mathrm{p}=0.007$ ) and by $2 \%$ in moderately old flies (OR $0.02 ; 95 \% \mathrm{CL}$ $(0.002-0.141) ; p=0.001)$ than in young flies [Table 3].

\section{[Table 3]}

\section{Molecular identification of trypanosomes species and sub-species}

Overall, Trypanosoma vivax (62.1\%) was the most prevalent species followed by $T$. congolense (all three sub types Kilifi, Forest and Savanna; 24.14\%), and T. brucei and T. simiae each at 6.89\% (Table 2). For T. brucei, further investigation was done by running a second PCR for diagnosis of T. b. gambiense employing a nested-PCR with a first reaction using TgsGP1/2 primers[29] and a second one with TgsGP sense2/antisense2 primers described by [30]. The results turned out negative, and since we did not expect the other Trypanozoons (T. evansi and T. $b$ rhodesiense) to be present in this geographical area, we concluded that the subspecies was T. brucei brucei. There were two cases of mixed infections with $T$. brucei brucei/T. vivax. The overall prevalence of the different species and sub-species in the two districts is shown in Figure 3.

\section{Blood meal identification}

A total of 34 blood-engorged flies' midgut samples were analyzed to determine the sources of the blood meal. Amplifications of the $\mathrm{CO} 1$ and cyt b genes on 1.8\% agarose gel all gave a $650 \mathrm{bp}$ and 359bp PCR products, respectively (Fig. 4).

\section{[Figure 4]}


Hosts were identified in 88.2\% (30/34) analyzed samples, with sequence identities ranging from $96-100 \%$ in homology with reference sequences in Genbank. The four samples consistently amplified tsetse DNA, implying probably degraded blood meal DNA. Tsetse hosts identified included cattle (14/30), Humans (8/30), Nile monitor lizard (5/30), African mud turtle (2/30) and the African savanna elephant (1/30) (Table 4).

\section{[Table 4]}

\section{Discussion}

This study assessed tsetse fly populations in Adjumani and Moyo Districts in northwestern Uganda, a known African trypanosomiasis endemic focus. The only species of tsetse caught was Glossina fuscipes fuscipes. This is probably because of the nature of our sampling scheme that mainly targeted the edges of major rivers and streams as well as peri-domestic environments. Glossina fuscipes fuscipesis is known to generally disperse along waterways, following riverbeds or the edges of gallery forests, where they are able to survive low humidity conditions during dry seasons [31-33]. Female flies were consistently higher than males in most traps in both Adjumani and Moyo Districts. This finding is similar to results of a survey in Mukono district, southeastern Uganda where the percentage of females was higher than that of males in all study months [34]. The high percentage of females than males caught by our traps could be due to the fact that there may have simply been more females than males in the study area, and thus our catches was representative of the sex ratio in the population [35]. Females are also known to be more prolific feeders; male flies feed every 3-4 days [36]whereas females take blood meals regularly due to their role in reproduction [37], which increases their chances of getting trapped as they seek for blood meals.

In the present work, we found no significant difference in apparent density between the two districts implying that the similarity in biotopes present favorable habitats for tsetse in both districts. The average AD we obtained in this study is similar to the findings by [38] in mid northern Uganda. However, it's lower than those reported in southeastern Uganda by [39]. This observed difference could be attributed to variations in the environmental and agro-ecological conditions and the season in the study areas. Northern and northwestern Uganda differ significantly in climate, especially in annual precipitation, from the south of the country [40]. Southern Uganda has a somewhat cooler climate and is less humid, with mean annual rainfall near Lake Victoria often exceeding $2100-3000$ mm; the high temperature varies by $2-3{ }^{\circ} \mathrm{C}$ over the year, with a mean daily high being around $26^{\circ} \mathrm{C}$. In the north and northwest, the rainfall is between 1000 and $2000 \mathrm{~mm}$, and temperature varies by $5^{\circ} \mathrm{C}$ over the year, with the mean daily high being $29^{\circ} \mathrm{C}$ [41]. The unique climatic background presents create different tsetse population dynamics, and may be responsible for the observed difference in $A D$.

Our results showed that $10.7 \%$ of tsetse flies in both Adjumani and Moyo Districts were infected by at least one trypanosome species. This figure is relatively high given that infection rates are known to be generally low in tsetse flies [42]. Other studies in Uganda have reported lower rates; [38] got an infection rate of 5.6\% in tsetse flies mid northern Uganda districts of Lira, Apac and Kole. [39] got an even lower rate (1.55\%) in southeastern Uganda, although their study was based on microscopic examination only. Our comparatively high infection rates can be explained by the fact that livestock owners in Adjumani and Moyo Districts are not keen on use of trypanocidal drugs due to high costs associated with purchase (Personal Communication, Mathias Dramwi, District Veterinary Officer Adjumani, 2019).

Our results also indicated that sex of fly had no significant association with infection rates. This contrast with the suggestion that fly sex appears to influence susceptibility to trypanosome infection. For example, male flies (Glossina morsitans morsitans, G. m. centralis, G. pallidipes, G. fuscipes fuscipes) have been shown to have higher 
rates of salivary gland infection with $T$. brucei than females [43-45], and it has been suggested that a sex-linked recessive gene is involved[44]. However, some studies suggest that female flies should have higher infection rates than males as they live longer than males and thus they have higher chances of getting infection [46]. Thus the precise associations of trypanosome infection with sex remain unresolved. Regardless, this study found no statistical difference in infection rates with sex.

Trypanosome infection rates were correlated with age, with older flies having a higher risk of infections than their younger counterparts. This is consistent with the observation that older flies have higher chances of having obtained infections from feeding on multiple hosts, and are capable of allowing the development of the parasites to infective stages [47]. Our results of ageing using wing fray technique indicated a relatively old population of approximately 30 days in Adjumani district and 25 days in Moyo district, which could also explain the relatively high overall infection rate in the two districts.

The most common trypanosome species in tsetse flies in the two districts was T. vivax, accounting for $67 \%$ of the examined samples. Magona et al. [48] found similar results in studies of Glossina fuscipes fuscipes tsetse flies in Southeast Uganda. In this study, our traps caught only Glossina fuscipes fuscipes, for which better competence in the transmission of T. vivax has been reported compared to G. pallidipes [49]. In addition, T. vivax is known to have a shorter developmental life cycle which is entirely completed in the 10 days in the proboscis, which may explain its predominance in the surveyed samples [50]. An earlier study by Angwech et al. [51] in Amuru and Nwoya districts, which border the study area in the present study, found that T. vivax was also the most predominant trypanosome species in cattle. Our results are also consistent with several other previous studies on tsetse and trypanosomes ecology in Uganda $[39,52,53]$.

We did not find any evidence of human infective trypanosomes in the tsetse flies sampled, in agreement with a recent epidemiological data reporting no cases in the neighbouring Arua and Koboko districts [54], all of which are within the same gambiense focus. It is possible that the transmission of T. b. gambiense has been decisively suppressed and prevalence reduced to near elimination. The driver behind this unprecedented decline has probably been the large active and passive screening programme by Ugandan National Sleeping Sickness Programme and Medecins Sans Frontiè res (MSF) France between 1987 and 2002 [55]. In West Nile, the last large-scale active screening was undertaken by MSF Spain and the Ministry of Health (MoH) supported by WHO in 2010 and 2011[18]. However, more extensive screening in the vectors is paramount given our relatively small sample size, since it's known that the prevalence of gambiense HAT disease amongst wild tsetse populations is often extremely low [5658].

In the present study, the sequence analysis of blood meals showed that the main hosts of tsetse was cattle, followed by humans, and other hosts like monitor lizard, African mud turtle and the African Savanna elephant. Glossina fuscipes fuscipes is known to be a non-preferential feeder, with blood meals taken from the most available hosts [59]. However, in Adjumani and Moyo districts, tsetse mostly feed on humans and cattle due to the fact that the environment is highly anthropized and wild animals are rare, except in Zoka forest, which has abundant wildlife, an area we did not sample. Another probable reason for the high cases of blood meal from cattle, and to some extent humans, is that this survey was done in the dry season when it is common that animals, especially cattle, are taken to the banks of rivers and streams to graze and drink water. As such, Glossina fuscipes fuscipes, a riverine species, gain access to the cattle and humans who attend to the animals and utilize the water for domestic and other uses. There was, however, one curious case of a blood meal taken from an elephant. This particular fly was trapped from Arinyapi sub-county in Adjumani district, which borders southern Sudan. Trans-boundary elephants especially from Nimule National Park in South Sudan that have on several occasions destroyed numerous acres of food crops 
belonging to hundreds of small-scale farmers in the two sub-counties of Arinyapi and Dzaipi [60] are seemingly potential hosts of Glossina tsetse. Results of blood meal analyses furthermore highlight the importance of reptiles, especially monitor lizards and African mud turtles, as important hosts for Glossina fuscipes fuscipes tsetse. Previous studies in southeastern Uganda $[39,59,61]$ and on the shores of Lake Victoria in Kenya [62] identified monitor lizards as an important food source for tsetse. It has been proposed that the preference for reptiles may simply reflect an ecological 'concordance' between flies and lizards; both are cold-blooded and probably with similar diurnal pattern in the environment where they co-exist [62]. Reptiles are even suspected to be natural cryptic reservoirs of human infective trypanosomes [63].

\section{Conclusion}

The present study has shown a moderately high infection rate at $10.78 \%$, with all infections attributed to trypanosome species that are causative agents of the animal disease only. The absence of detection of human infective trypanosomes in the tsetse flies indicates that HAT may not be so highly prevalent in this endemic focus anymore. However, this result has to be validated using large-scale passive and active seasonal entomological and human screening. Cattle and humans appear to be the most important tsetse blood meals sources in the region and should be considered in the design of tsetse and trypanosomiasis control interventions.

\section{Abbreviations}

$A D$

Apparent Density; COI:Cytochrome Oxidase I; FAO:Food and Agricultural Organization; HAT:Human African Trypanosomiasis; AAT:Animal African Trypanosomiasis; OD:Optical Density; PCR:Polymerase Chain Reaction; TgsGP: Trypanosoma gambiense specific Glycoprotein; WHO:World Health Organization

\section{Declarations}

\section{Acknowledgements}

The authors are highly indebted to the MSI Diagnostics Project at Gulu University, and the African Biosciences Challenge Fund Fellowship for financial and logistical support. We also wish to acknowledge the Biosciences Eastern and Central Africa (BecA)-ILRIHub, Nairobi for providing laboratory space and allowing us to use their facilities for molecular analysis of the samples. Management of Gulu University is also highly acknowledged for granting R01 leave to undertake laboratory work at the BecA-ILRI Hub laboratories in Nairobi, Kenya. Thanks also go to the technicians (Mr. Okello Alfonse and Mr. Khizza Constant), and to the District Entomologists and the District Veterinary Officers of Adjumani and Moyo districts for assistance with fieldwork.

\section{Authors' contributions}

R01, RE and EAO conceived and designed the study. R01, MN, and MM collected data and performed the lab analyses. R01, RO2 performed initial analyses and wrote initial draft of manuscript. GMM, EN, RE, EAO, FAO, AH and $\mathrm{GO}$ critically revised the manuscript. All authors read and approved the final version of the manuscript.

\section{Funding}

This study was supported financially by the Gulu University MSI Trypanosome Diagnostics Project (Project no: MSI/WAI/3/29/2010) and by the African Biosciences Challenge Fund Fellowship (ABCF) award to R01. The funders 
had no role in study design, data collection and analysis, decision to publish, or preparation of the manuscript.

\section{Availability of data and materials}

The data supporting the conclusion of this study is available from the link: https://osf.io/jhtu3/quickfiles.

\section{Ethics approval and consent to participate}

This research was approved by the Gulu University Institutional Review Board and by the Uganda National Council for Science and Technology.

\section{Consent for publication}

Not applicable.

\section{Competing interests}

The authors declare that they have no competing interests.

\section{Authors' details}

${ }^{1}$ Department of Biology, Faculty of Science, Gulu University, P.O Box 166, Gulu, Uganda. ${ }^{2}$ Department of Biology, Faculty of Science, Muni University, P.O Box 725, Arua, Uganda. ${ }^{3}$ Department of Biosystems Engineering, Faculty of Agriculture and Environment, Gulu University, P. O Box 166, Gulu, Uganda. ${ }^{4}$ Biosciences Eastern and Central AfricaInternational Livestock Research Institute Hub, P. O Box 30709, Nairobi, Kenya. ${ }^{5}$ Department of Molecular Biology, College of Veterinary Medicine, Animal Resources and Biosecurity, Makerere University, P.O Box 7062, Kampala, Uganda. ${ }^{6}$ Department of Biology, University of Eastern Finland, P. O. Box 11180101 Joensuu, Finland.

\section{References}

1. Franco JR, Cecchi G, Priotto G, Paone M, Diarra A, Grout L. ... Argaw D(. Monitoring the elimination of human African trypanosomiasis: update to 2014. PLoS neglected Trop Dis. 2017;11:e0005585.

2. WHO. WHO Fact Sheet [Internet]. 2017. Available: https://www.who.int/news-room/fact-sheets/detail/diarrhoealdisease.

3. Okello WO, Muhanguzi D, MacLeod ET, Welburn SC, Waiswa C, Shaw AP. Contribution of draft cattle to rural livelihoods in a district of southeastern Uganda endemic for bovine parasitic diseases: an economic evaluation. Parasit Vectors Springer. 2015;8:571.

4. Muhanguzi D, Okello WO, Kabasa JD, Waiswa C, Welburn SC, Shaw APM. Cost analysis of options for management of African Animal Trypanosomiasis using interventions targeted at cattle in Tororo District; southeastern Uganda. Parasit Vectors. Springer; 2015;8: 387.

5. Murray MGA. The current situation on animal trypanosomiasis in Africa. Prev Vet Med. 1984;2:23-30.

6. Swallow B. Impacts of African animal trypanosomosis on migration, livestock and crop production. Nairobi, ILRI. 1998; 1-19.

7. Fèvre EM, Coleman PG, Odiit M, Magona JW, Welburn SC, Woolhouse MEJ. The origins of a new Trypanosoma brucei rhodesiense sleeping sickness outbreak in eastern Uganda. Lancet. 2001;358:625-8. doi:10.1016/S01406736(01)05778-6. 
8. Fevre EM, Coleman PG, Odiit MD, Magona JWSMW. The origins of a new sleeping sickness outbreak (caused by Trypanosoma brucei infection) in eastern Uganda. Lancet. 2001;358.

9. Selby R, Bardosh K, Picozzi K, Waiswa C, Welburn CS. Cattle movments and trypanosomes: restocking efforts and the spread of Trypanosoma brucei rhodesiense sleeping sickness in post-conflict Uganda. Parasit Vectors. 2013;6:281-303.

10. Opiro R, Saarman NP, Echodu R, Opiyo EA, Dion K, Halyard A, ... Caccone A. Genetic diversity and population structure of the tsetse fly Glossina fuscipes fuscipes (Diptera: Glossinidae) in Northern Uganda: Implications for vector control. PLoS Negl Trop Dis. 2017;11.

11. Echodu R, Sistrom M, Hyseni C, Enyaru J, Okedi L, Aksoy S, et al. Genetically distinct Glossina fuscipes fuscipes populations in the Lake Kyoga region of Uganda and its relevance for human African trypanosomiasis. Biomed Res Int. 2013;2013:614721. doi:10.1155/2013/614721.

12. Beadell JS, Hyseni C, Abila PP, Azabo R, Enyaru JCK, Ouma JO, et al. Phylogeography and Population Structure of Glossina fuscipes fuscipes in Uganda: Implications for Control of Tsetse. PLoS Negl Trop Dis. 2010;4:e636. doi:10.1371/journal.pntd.0000636.

13. Solano P, Kaba D, Ravel S, Dyer N, Sall B, Vreysen MJB, et al. Population genetics as a tool to select tsetse control strategies: Suppression or eradication of Glossina palpalis gambiensis in the niayes of senegal. PLoS Negl Trop Dis. 2010;4:1-11. doi:10.1371/journal.pntd.0000692.

14. Jordan AM. Trypanosomiasis control and African rural development. London: Longman; 1986.

15. Stich A, Barret MP. and KS. Waking up to sleeping sickness. Trends Parasitol. 2003;19:195-7.

16. Rogers DJ. Tsetse population dynamics and distribution: a new analytical approach. J Anim Ecol. 1979;48:825 $-849$.

17. Laveissière C, Penchenier L. Manuel de lutte contre la maladie du sommeil. IRD éditions; 2005.

18. Selby R, Wamboga C, Erphas O, Mugenyi A, Jamonneau V, Waiswa C, et al. Gambian human African trypanosomiasis in North West Uganda. Are we on course for the 2020 target? PLoS Negl Trop Dis. Public Library of Science; 2019;13.

19. Challier A, Laveissiere C. A new trap for capturing Glossina flies (Diptera: Muscidae), description and field trials. Cah ORSTOM Entomol Med Parasitol. 1973;11:251-62.

20. Williams B, Dransfield RBR. Tsetse fly (Diptera: Glossinidae) population dynamics and the estimation of mortality rates from life-table data. Bull Entomol Res. 1990;80:479-85.

21. Laveissière C, Grébaut P, Herder SPL. Les glossines vectrices de la Trypanosomiase humaine. F. rance LouisJean Ed. 2000.

22. Jackson CHN. An artificially isolated generation of tsetse flies (Diptera). Bull Entomol Res. 37: 291.

23. FAO. Training Manual for Tsetse Control Personnel. Food and Agriculture Organisation of the United Nations (FAO). Rome.; 1979.

24. Cox A, Tilley A, McOdimba F, Fyfe J, Eisler M, Hide G, Welburn S. A PCR based assay for detection and differentiation of African trypanosome species in blood. Exp Parasitol. 2005;11:24-9.

25. Muturi CN, Ouma JO, Malele II, Ngure RM, Rutto JJ, Mithöfer KM, et al. Tracking the feeding patterns of tsetse flies (Glossina genus) by analysis of bloodmeals using mitochondrial cytochromes genes. PLoS One. Public Library of Science; 2011;6.

26. Ivanova NV, Zemlak TS, Hanner RH, Hebert PDN. Universal primer cocktails for fish DNA barcoding. Mol Ecol Notes Wiley Online Library. 2007;7:544-8. 
27. Kocher TD, Thomas WK, Meyer A, Edwards SV, Pääbo S, Villablanca FX, et al. Dynamics of mitochondrial DNA evolution in animals: amplification and sequencing with conserved primers. Proc Natl Acad Sci National Acad Sciences. 1989;86:6196-200.

28. Altschul SF, Gish W, Miller W, Myers EW, Lipman DJ. Basic local alignment search tool. J Mol Biol Elsevier. 1990;215:403-10.

29. Radwanska M, Claes F, Magez S, Magnus E, Perez-Morga D, Pays E, et al. Novel primer sequences for polymerase chain reaction-based detection of Trypanosoma brucei gambiense. Am J Trop Med Hyg ASTMH. 2002;67:289-95.

30. Morrison LJ, Tait A, McCormack G, Sweeney L, Black A, Truc P, et al. Trypanosoma brucei gambiense Type 1 populations from human patients are clonal and display geographical genetic differentiation. Infect Genet Evol Elsevier. 2008;8:847-54.

31. Leak SGA. Tsetse biology and ecology: their role in the epidemiology and control of trypanosomosis. Wallingford.: CAB I Publishing, Wallingford; 1999.

32. Bouyer J, Guerrini L, César J, De La Rocque S, Cuisance D. A phyto-sociological analysis of the distribution of riverine tsetse flies in Burkina Faso. Med Vet Entomol Wiley Online Library. 2005;19:372-8.

33. Opiro R, Saarman NP, Echodu R, Opiyo EA, Dion K, Halyard A. Evidence of temporal stability in allelic and mitochondrial haplotype diversity in populations of Glossina fuscipes fuscipes (Diptera: Glossinidae) in northern Uganda. Parasit Vectors Parasites Vectors; 2016; 1-12. doi:10.1186/s13071-016-1522-5.

34. Katunguka-Rwakishaya E, Kabagambe EK. Tsetse survey in Mukono district, south-east Uganda: population structure, distribution and blood meal status. Trop Anim Health Prod. 1996;28:151.

35. Leak SGA, Ejigu D, Vreysen MJB. Collection of entomological baseline data for tsetse area-wide integrated pest management programmes. Food and Agriculture Organization of the United Nations (FAO); 2008.

36. Davies H. 'Tsetse flies Nigeria.' Ibadan: Oxford University Press, Ibadan.; 1977.

37. Moloo SK. Aspects of the nutrition of adult female Glossina morsitans during pregnancy. J Insect Physiol Elsevier. 1976;22:563-7.

38. Azabo R, Abila P, Odhiambo L, Waiswa C. FE and LO. Trypanosome Infection rates in tsetse (Glossina fuscipes fuscipes) in communal grazing lands in Mid-northern Uganda. Online J Vet Res. 2016;20:225-36.

39. Waiswa C, Picozzi K, Katunguka-Rwakishaya E, Olaho-Mukani W, Musoke RA, Welburn SC. Glossina fuscipes fuscipes in the trypanosomiasis endemic areas of south eastern Uganda: apparent density, trypanosome infection rates and host feeding preferences. Acta Trop Elsevier. 2006;99:23-9.

40. Aksoy S, Caccone A, Galvani AP, Okedi LM. Glossina fuscipes populations provide insights for human African trypanosomiasis transmission in Uganda. Trends Parasitol Elsevier Ltd. 2013;29:394-406. doi:10.1016/j.pt.2013.06.005.

41. Basalirwa CP. Delineation of Uganda into Climatological rainfall zones using the method of principal component analysis. Int J Climatol. 1995;15:1161-77.

42. S A. Control of tsetse flies and trypanosomes using molecular genetics. Vet Parasitol. 2003;115: 125-145.

43. Dale C, Welburn SC, Maudlin I, Milligan PJM. The kinetics of maturation of trypanosome infections in tsetse. 111. Parasitology: Cambridge University Press; 1995. pp. 187-91.

44. Maudlin I, Welburn SC, Milligan P. Salivary gland infection: a sex-linked recessive character in tsetse? Acta Trop. Elsevier; 1990;48: 9-15. 
45. Moloo SK, Sabwa CL, Kabata JM. Vector competence of Glossina pallidipes and G. morsitans centralis for Trypanosoma vivax, T. congolense and T. b. brucei. Acta Trop. Elsevier; 1992;51: 271-280.

46. MIHOK S, Munyoki ELI, BRETT RA, JONYO JF, MAJIWA RÖTTCHERD. PAO, et al. Trypanosomiasis and the conservation of black rhinoceros (Diceros bicornis) at the Ngulia Rhino sanctuary, Tsavo West National park, Kenya. Afr J Ecol Wiley Online Library. 1992;30:103-15.

47. Wijers DJB. Factors that may Influence the Infection Rate of Glossina Palpalis with Trypanosoma Gambiense: I. -The Age of the Fly at the Time of the Infected Feed. Ann Trop Med Parasitol Taylor Francis. 1958;52:385-90.

48. Magona JW, Walubengo J, Odiit M, Okedi LA, Abila P, Katabazi BK, et al. Implications of the re-invasion of Southeast Uganda by Glossina pallidipes on the epidemiology of bovine trypanosomosis. Vet Parasitol Elsevier. 2005;128:1-9.

49. Moloo SK, Kutuza SB, Boreham PFL. Studies on Glossina pallidipes, G. fuscipes fuscipes and G. brevipalpis in terms of the epidemiology and epizootiology of trypanosomiases in south-eastern Uganda. Ann Trop Med Parasitol Taylor Francis. 1980;74:219-37.

50. Jordan AM. Recent developments in the ecology and methods of control of tsetse flies (Glossina spp.)(Dipt., Glossinidae)-a review. Bull Entomol Res. Cambridge University Press; 1974;63: 361-399.

51. Angwech H, Nyeko JHP, Opiyo EA, Okello-Onen J, Opiro R, Echodu R, et al. Heterogeneity in the prevalence and intensity of bovine trypanosomiasis in the districts of Amuru and Nwoya, Northern Uganda. BMC Vet Res BioMed Central. 2015;11:255.

52. Biryomumaisho S, Rwakishaya E-K, Melville SE, Cailleau A, Lubega GW. Livestock trypanosomosis in Uganda: parasite heterogeneity and anaemia status of naturally infected cattle, goats and pigs. Parasitol Res Springer. 2013;112:1443-50.

53. Waiswa C, Olaho-Mukani W, Katunguka-Rwakishaya E. Domestic animals as reservoirs for sleeping sickness in three endemic foci in south-eastern Uganda. Ann Trop Med Parasitol. Taylor \& Francis; 2003;97: 149-155.

54. Cunningham LJ, Lingley JK, Tirados I, Esterhuizen J, Opiyo M, Mangwiro CTN, et al. Evidence of the absence of human African trypanosomiasis in two northern districts of Uganda: Analyses of cattle, pigs and tsetse flies for the presence of Trypanosoma brucei gambiense. PLoS Negl Trop Dis Public Library of Science. 2020;14:e0007737.

55. Priotto GKW. Final evaluation of the MSF-France Trypanosmiasis control programme in West Nile, Uganda. From 1987 to 2002. Epicentre. 2002.

56. Jamonneau V, Ravel S, Koffi M, Kaba D, Zeze DG, Ndri L, et al. Mixed infections of trypanosomes in tsetse and pigs and their epidemiological significance in a sleeping sickness focus of Cote d'Ivoire. 129. Parasitology: Cambridge University Press; 2004. pp. 693-702.

57. Farikou O, Njiokou F, Simo G, Asonganyi T, Cuny G, Geiger A. Tsetse fly blood meal modification and trypanosome identification in two sleeping sickness foci in the forest of southern Cameroon. Acta Trop Elsevier. 2010;116:81-8.

58. Kagbadouno MS, Camara M, Rouamba J, Rayaisse J-B, Traore IS, Camara O, et al. Epidemiology of sleeping sickness in Boffa (Guinea): where are the trypanosomes? PLoS Negl Trop Dis. Public Library of Science; $2012 ; 6$.

59. Clausen PH, Adeyemi I, Bauer B, Breloeer M, Salchow F, Staak C. Host preferences of tsetse (Diptera: Glossinidae) based on bloodmeal identifications. Med Vet Entomol. 1998;12:169-80.

60. Sharon Lenia. UWA Officials Move to Control Influx of Elephants from South Sudan [Internet]. 2014 [cited 20 Feb 2020] p. Uganda Radio Network. Available: https://ugandaradionetwork.com/story/uwa-officials-move-tocontrol-influx-of-elephants-from-south-sudan\#ixzz3oenLNdyG).

Page $13 / 20$ 
61. Okoth JO, Kapaata R. Trypanosome infection rates in Glossina fuscipes fuscipes Newst. in the Busoga sleeping sickness focus, Uganda. Ann Trop Med Parasitol Taylor Francis. 1986;80:459-61.

62. Mohamed-Ahmed MM, Odulaja A. Diel activity patterns and host preferences of Glossina fuscipes fuscipes (Diptera: Glossinidae) along the shores of Lake Victoria, Kenya. Bull Entomol Res. Cambridge University Press; 1997;87: 179-186.

63. Njagu Z, Mihok S, Kokwaro E, Verloo D. Isolation of Trypanosoma brucei from the monitor lizard (Varanus niloticus) in an endemic focus of Rhodesian sleeping sickness in Kenya. Acta Trop Elsevier. 1999;72:137-48.

\section{Tables}

Table 1: Results of entomological surveys

\begin{tabular}{|llllllllll|}
\hline District & & & & No of traps & & & & MWFV \\
& Village & $\mathbf{X}$ & $\mathbf{Y}$ & & Male & Female & Total & FTD \\
\hline Adjumani & Olwi & 3.149863 & 31.681045 & 10 & 10 & 18 & 28 & 0.93 & 3.8 \\
& Osugo East & 3.200765 & 31.722688 & 10 & 32 & 49 & 81 & 2.70 & 2.8 \\
\hline & Olobo & 3.384375 & 32.011374 & 12 & 55 & 60 & 115 & 3.19 & 4.3 \\
\hline & Oringya & 3.486135 & 32.010335 & 11 & 14 & 21 & 35 & 1.06 & 4.5 \\
\hline & Pagirinya & 3.377809 & 31.994145 & 10 & 29 & 32 & 61 & 2.03 & 3.6 \\
\hline & Ori & 3.647330 & 31.789970 & 10 & 10 & 29 & 39 & 1.30 & 4.2 \\
\hline & Orubakulem & 3.691983 & 31.780385 & 13 & 64 & 79 & 143 & 3.67 & 3 \\
\hline & Lea & 3.592517 & 31.606833 & 11 & 30 & 49 & 79 & 2.39 & 2.8 \\
\hline & Cefo & 3.605500 & 31.651733 & 10 & 12 & 8 & 20 & 0.67 & 3.5 \\
\hline
\end{tabular}

*MWFV refers to Mean Wing Fray Value; $X$ and $Y$ refer to the values of $X$ and $Y$ coordinates of the villages

Table 2: Rate of trypanosome infection in the villages of Moyo and Adjumani districts, northwestern Uganda 


\begin{tabular}{|lllllllll|}
\hline District & Village & $\begin{array}{l}\text { Total } \\
\text { examined }\end{array}$ & $\begin{array}{l}\text { Total } \\
\text { infected }\end{array}$ & $\begin{array}{l}\text { Infection } \\
\text { rate (\%) }\end{array}$ & T. vivax & T. brucei & T. simiae & $\begin{array}{l}\text { T. } \\
\text { Congolense }\end{array}$ \\
\hline Adjumani & Olwi & 12 & 0 & 0 & 0 & 0 & 0 & 0 \\
& Osugo East & 35 & 4 & 11.42 & 3 & 0 & 0 & 1 \\
\hline & Olobo & 60 & 11 & 18.33 & 7 & 1 & 1 & 2 \\
\hline & Oringya & 14 & 2 & 14.2 & 1 & 0 & 0 & 1 \\
\hline & Pagirinya & 29 & 1 & 3.45 & 1 & 0 & 0 & 0 \\
\hline & Ori & 16 & 1 & 6.25 & 1 & 0 & 0 & 0 \\
\hline Total & Orubakulem & 60 & 7 & 11.67 & 3 & 1 & 1 & 2 \\
\hline & Lea & 30 & 3 & 10 & 2 & 0 & 0 & 1 \\
\hline
\end{tabular}

Table 3: Results of binary logistic regression of infection rate and wing fray (WF) categories

\begin{tabular}{|llll|}
\hline Age category & N & Odds ratio (95\% Cl) & $P$ \\
\hline Young tsetse (WF 1-2) & 249 & 1 & Reference \\
\hline Moderately tsetse (WF 3-4) & 337 & $0.02(0.002-0.141)$ & 0.001 \\
\hline Very old tsetse (WF 5-6) & 36 & $0.28(0.108-0.702)$ & 0.007 \\
\hline Total & 622 & & \\
\hline
\end{tabular}

${ }^{*} N$ number of tsetse examined for infections. Young tsetse were used as a reference category

Table 4: Details of identification and accession numbers for all reference sequences for COI and cytb gene sequences generated 


\begin{tabular}{|llll|}
\hline Host species identified & $\begin{array}{l}\mathbf{N}(\mathbf{n}=30) \\
\text { Humans (Homo sapiens) }\end{array}$ & $\begin{array}{l}\text { Closest match on } \\
\text { BLAST - } \\
\text { Genbank ID (COI) }\end{array}$ & $\begin{array}{l}\text { Closest match on BLAST - Genbank } \\
\text { ID (Cyt b) }\end{array}$ \\
& 08 & $\begin{array}{l}\text { JF739540.1 } \\
\text { JQ705025.1 }\end{array}$ & AY509658 \\
& & GU123040.1 & HM036565 \\
& & JQ704657.1 & GU123040.1 \\
\hline Varanusniloticus & 05 & HQ219067.1 & ND \\
& & AB185327.1 & \\
\hline Cattle (Bos taurus) & & HQ219069.1 & \\
& 14 & JN817351 & EU365345 \\
& & JN817314 & AY682374 \\
& & JN817330 & EU365345 \\
\hline Pelusios chapini & & JN817351 & \\
\hline $\begin{array}{l}\text { African Savanah Elephant (Loxodonta } \\
\text { africana) }\end{array}$ & 01 & AB443879.1 & AY768855 \\
\hline
\end{tabular}

*Data combine both cytb and COI, and GenBank accession numbers for representative sequences given, and where not determined indicated as ND.

\section{Figures}




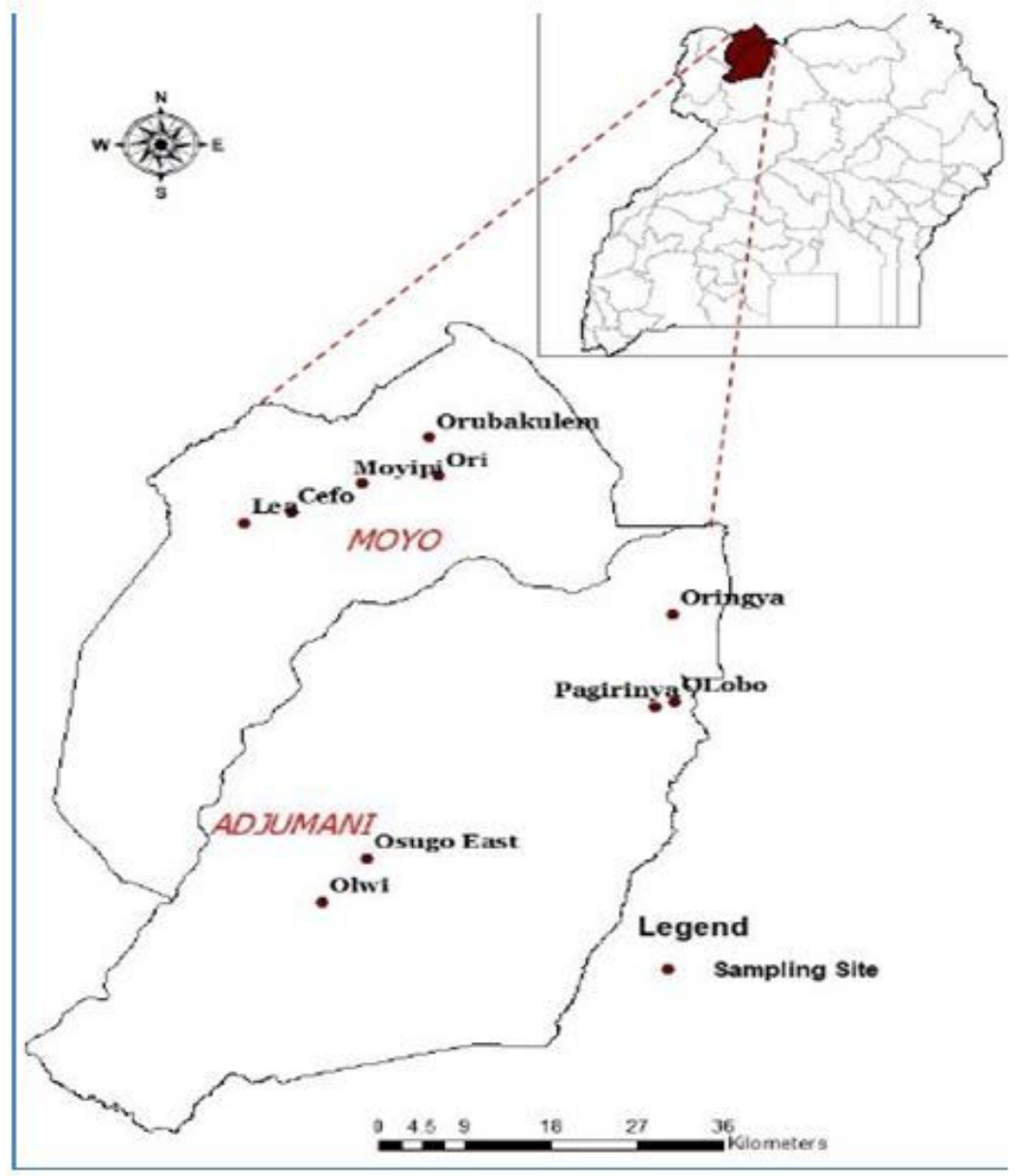

Figure 1

Map of study area showing sampled villages. Map was created by the authors using ArcGIS version 10.3.1. 


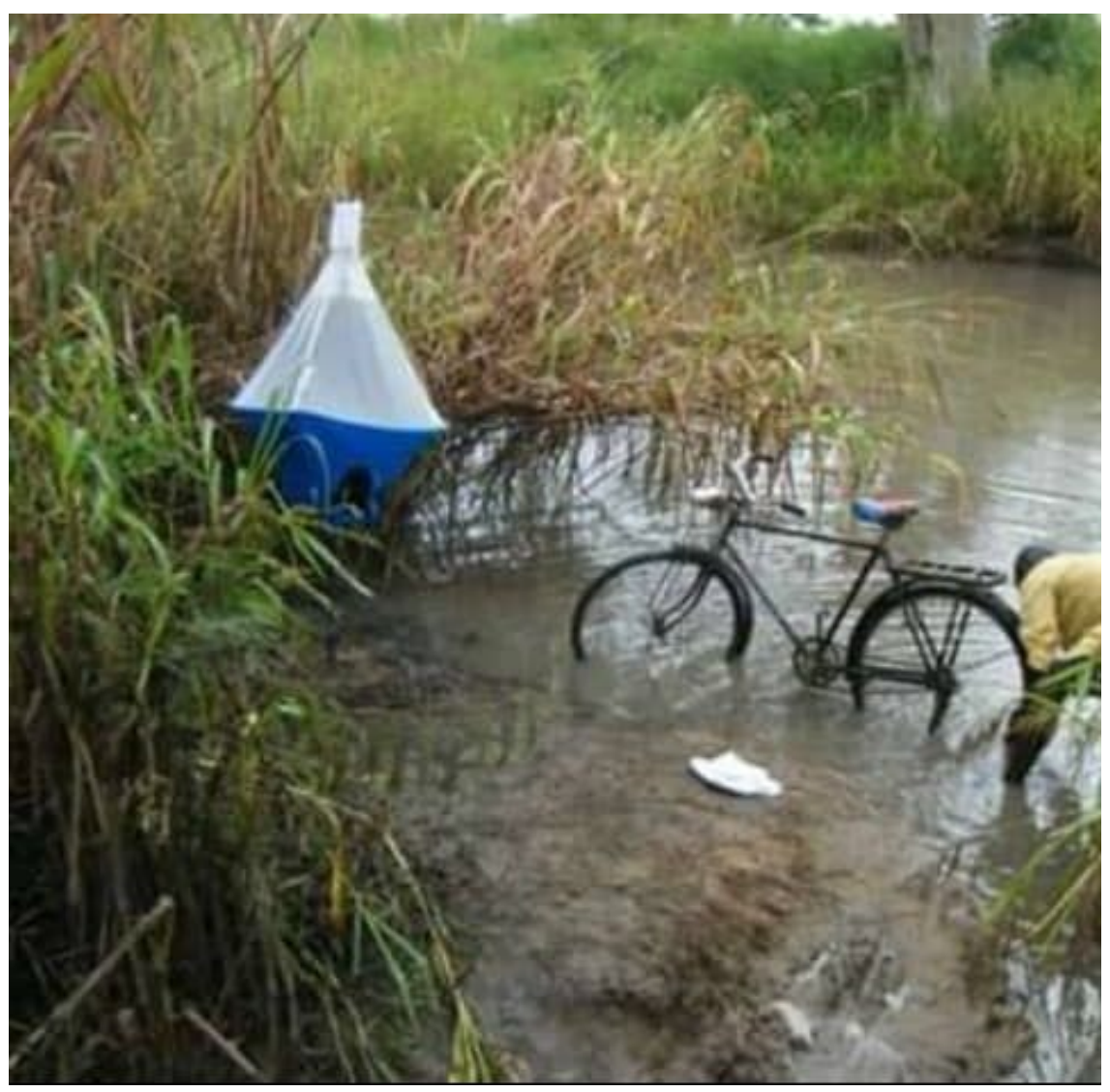

\section{Figure 2}

A biconical trap baited with cow urine and acetone to enhance trapping efficiency deployed along a river in the study area. 


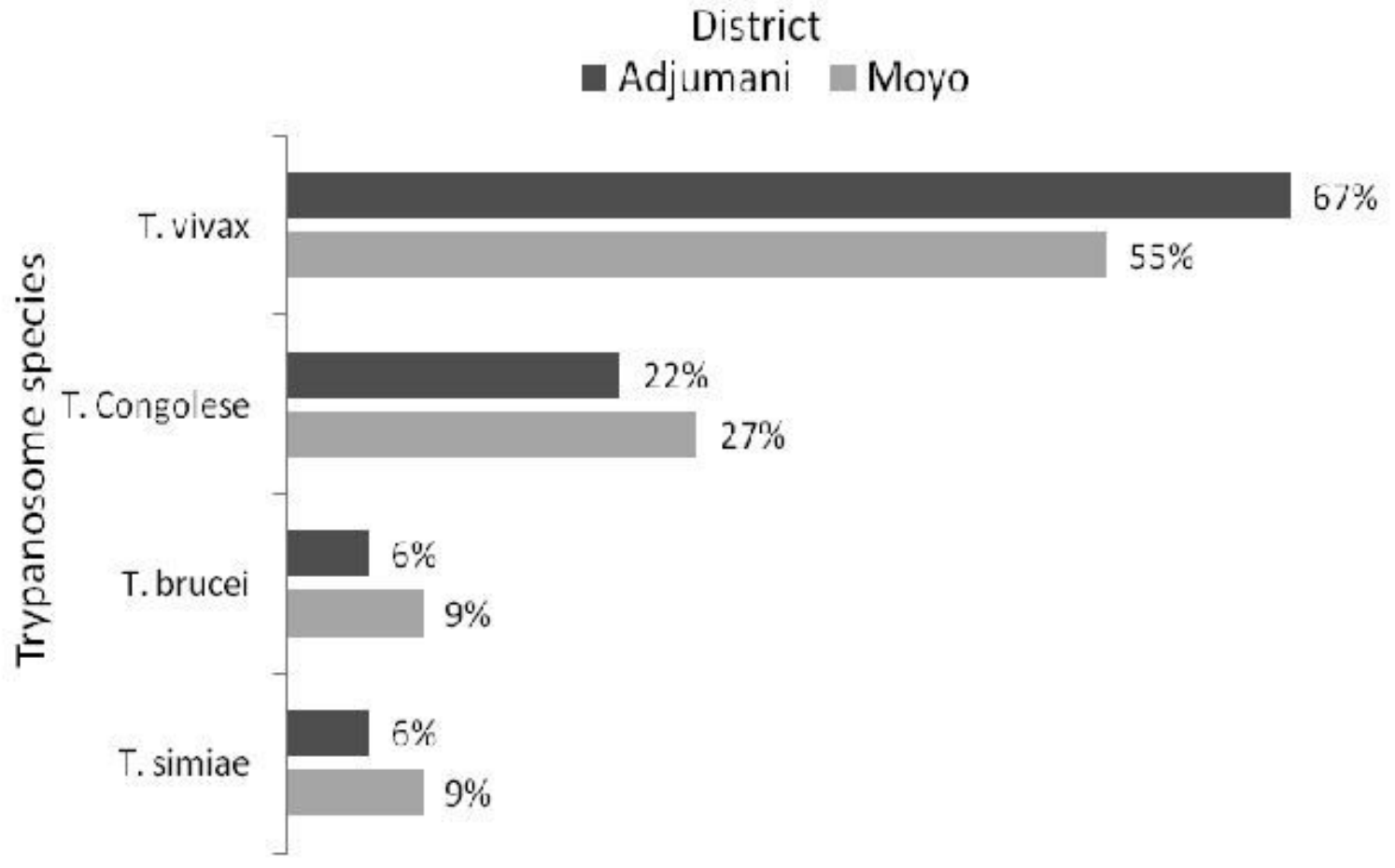

\section{Figure 3}

Overall prevalence of the different trypanosome species and subspecies in Moyo and Adjumani Districts, Northwestern Uganda.
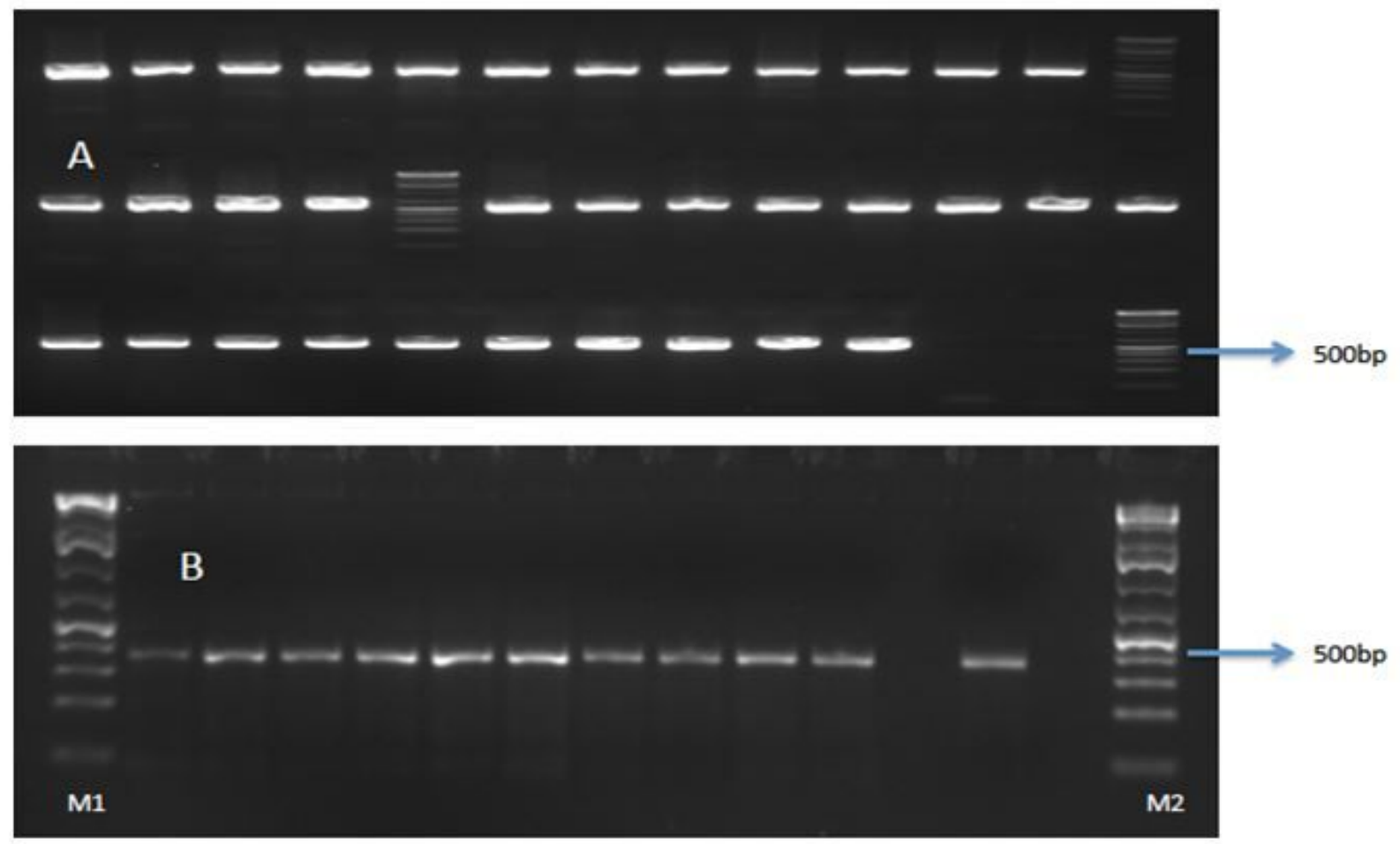


\section{Figure 4}

Representative gel photograph showing 650bp (A) and $359 \mathrm{bp}(\mathrm{B})$ fragments size of $\mathrm{COI}$ and cyt b gene amplification products. Lanes M1, M2: 75 bp marker. 